\title{
An Assessment of Consumer Ethnocentrism Tendencies Scale among University Students: The case of Turkish and Bosnian Students
}

\author{
Merjema Becic \\ International University of Sarajevo
}

\begin{abstract}
The process of globalization and liberalization of markets brought new challenges and opportunities for both, local and global businesses. A number of studies explored consumer ethnocentric tendencies by making use of CETSCALE, universally accepted measure of the phenomenon developed by Shimp and Sharma in 1987. The present study aims to explore levels of consumer ethnocentrism among university students studying at the International University of Sarajevo using the quantitative research method utilizing the survey originally developed by Shimp and Sharma consisting of 17 questions for inferential statistics, plus four questions added by the author for descriptive statistics to explain differences arising due to demographic characteristics of respondents, including nationality, gender, age and income level. Research was carried out in cross-sectional timeframe study manner utilizing convenience sampling methodology. The questionnaire responses were collected from 150 respondents; freshmen and postgraduate Turkish and Bosnian students in paper form. The CETSCALE value of 79.60 for Bosnian students compared to 74.22 for Turkish indicates that Bosnian students tend to be slightly more ethnocentric consumers than Turkish. Additionally, value of CETSCALE of 84.37 for postgraduates compared to 74.24 for freshmen indicates positive relationship between level of consumer ethnocentrism and level of education. Comparing results with those obtained by other researchers in developed countries, both Bosnian and Turkish students showed higher levels of consumer ethnocentrism. High preference for domestic products expressed by Bosnian students might be a signal for domestic companies to focus more on this population in terms of adjusting their products and marketing activities.
\end{abstract}

Keywords: Consumer ethnocentrism, CETSCALE, Consumer behavior, Globalization.

\section{INTRODUCTION}

As markets become borderless and fully integrated, it is important to understand whether consumers are concerned about a product's country of origin or to what extent nations and cultures prefer domestic products as opposed to foreign 
goods. Ethnocentrism is defined by the Webster's dictionary as 'an attitude that one's own group (race or people) is superior'. It represents a "tendency to see an individual's own group as the center of the universe, to interpret other social units from a group perspective and to reject those people who are culturally different, blindly accepting those who are culturally similar" (Sainy\&Jangalani, 2012).

Consumer ethnocentrism has increasingly been of interest for researchers in the area of consumer behavior and international marketing, as its implications for marketers have shown to be of great importance, since it directly influences consumers' attitudes and buying preferences.Buying foreign products is perceived wrong as it is believed to be harmful to the domestic economy, unpatriotic and as having an adverse impact on the domestic employment (Akdogan et al., 2012). Consumer ethnocentrism in certain cases transcends mere economic and functional considerations, but has a more noble foundation rooted in morality. Some consumers believe it is unpatriotic and wrong to purchase foreign-made products because it will hurt the domestic economy and cause loss of jobs. Highly ethnocentric consumers often make biased judgments and over-evaluate domestic products unreasonably in comparison with foreign products.

Shimp and Sharma (1987) have noted that "consumer ethnocentrism gives the individual a sense of identity, feelings of belonging, and, most importantly, an understanding of what purchase behavior is acceptable or unacceptable to the in-group". On the other side, consumers who are non-ethnocentric judge foreign products on their merits without consideration of where these products are made. Several antecedents of consumer ethnocentrism have been identified by various studies. Consumers who tend to be less ethnocentric are those who are young, those who are male, those who are better educated, and those with higherincome levels. Sharma et al. (1995) argue that people from the developed and first world countries tend to be less ethnocentric than their counter part in developing and emerging nations.

Being defined as the „belief held by consumer about the appropriateness, indeed morality of purchasing foreign-made products"(Shimp\& Sharma, 1987), consumer ethnocentrism has been assessed in many countries with different levels of development and included groups with different demographic characteristics, with the accent on the markets where there is a fierce competition between domestic and foreign-made products, i.e. in the emerging markets. The concept of consumer ethnocentrism has significant managerial implications within the international business context.

A large proportion of the research has used the same tool for assessing the levels of consumer ethnocentrism around the 
world which is the so-called CETSCALE developed by Shimp and Sharma in 1987. Although results have shown that consumer ethnocentrism impacts consumer behavior regarding foreignmade products, it is observed that the results are not consistent across nations and cultures. Therefore, there is a need for replicative studies in the area. Additionally, variations exist between different social classes within one nation, as well as the other demographic characteristics. Shimp and Sharma (1987) had found those in the lower socio-economic group to be more ethnocentric than those higher up. They attributed this to the fear of losing jobs to foreign competitors.Regarding other demographic characteristics, the dominant view is that older people tend to be more ethnocentric consumers than younger. Additionally, people with higher levels of education are, in general, less ethnocentric compared to those with less education. When it comes to the level of income, the findings are split. Regarding the gender, it is concluded that women will be more ethnocentric consumers than men.

The present researchexplores the level of consumer ethnocentrism as measured by the CETSCALE among Bosnian and Turkish university students. To the author's knowledge, so far there has not been similar comparative research that would include these specific groups from the two nations, and which would yield findings significant to marketers in two countries, as it shows whether this particular group has tendency to buy domestic or imported goods, as well as the difference in ethnocentric attitudes due to the gender, nationality, income, and education level.

The purpose of this study is to examine the level of consumer ethnocentrism among Bosnian and Turkish students studying at the International University of Sarajevo and its relationship with respondents' demographic characteristics including nationality, gender, incomelevel and year of studying. Consumer ethnocentrism level will be measured by the CETSCALE, which is 17 - item Likerttype 7-point scale developed and tested by Shimp and Sharma in 1987 , and it is used in many countries, so far, to assess consumers' ethnocentric tendencies.

The study has both comparative and explanatory objectives. Comparative data allows a researcher to explore the validity of the concept and measure across two nations and cultures, and to compare attitudes and behaviors of comparable groups in two countries. On the other side, investigating relationship between consumer ethnocentrism and demographic variables might help and provide guidance for companies operating in the Bosnian and Turkish market. 


\section{LITERATURE REVIEW}

Prior to 1966, no significant research on the topic of ethnocentrism was conducted.In 1966, applied statisticians Pearson and Zaltman were the first to propose the idea of conceptualization of ethnocentrism. Later, in 1987, Shimp and Sharma focused on customers' ethnocentric tendency and in that way were the first to incorporate the study of ethnocentrism in the field of marketing. In their work, Shimp and Sharma developed consumer ethnocentric tendency scale (CETSCALE) as a universal measure of consumer ethnocentrism, which has extensively been used and confirmed by researchers to assess customers' ethnocentric tendencies.

The validity and reliability of the measure has so far been assessed by many authors and for different markets. Martinez, Zapata and Garcia (2000) validated CETSCALE as a measure of Spanish consumers' ethnocentric tendencies by means of confirmatory factor analysis adopting a competing models strategy. Their conclusion was that the scale measures a unidimensional construct and that the measurement error is quite acceptable.

Terblanche, Pentz and Boshoff (2013) surveyed two subsamples, namely a sample of white and a sample of black South African respondents to account for the ethnic diversity in South Africa. Results indicate that the CETSCALE should be regarded as a multi-dimensional measuring instrument for South Africa.

The unidimensionality postulate of the CETSCALE was confirmed by Sepehr and Kafashpoor (2012) who assessed validity and reliability of the CETSCALE in the context of Iran on the sample of 278 university students to examine the unidimensionality, internal consistency, discriminant validity, and nomological validity of the CETSCALE. They found reliability and discriminant validity of the CETSCALE strongly supported by the data, while the support for nomological validity was not very strong. Chowdhury and IbnRahman (2014) tested the applicability of CETSCALE in a developing country Bangladesh. Based on 788 samples collected from 27 districts of Bangladesh, they proved applicability of the scale on three chosen socio-demographic groups namely, students, job holders, and businessmen.

So far, the research has been conducted for countries with various development levels and included different demographic groups including USA, Japan, Germany, Russia, Sweden, Turkey, Czech Republic, Bosnia and Herzegovina, Montenegro, Croatia, New Zealand, etc. The repeated conclusion of the research conducted by various researchers was that consumers from the developed countries in general tend to be more ethnocentric, (Good \& Huddleston, 1995; Durvasula, Andrews \& Netemeyer, 1997), while consumers from developing countries have repeatedly shown marked preference for imported goods (Papadopoulos, 
Heslop \& Beraes, 1990; Agbonifoh\&Eliminian, 1994; Mohammad et al., 2000).

A good summary of antecedents of consumer ethnocentrism found in previous studies on the topic is presented by Jain and Jain (2013) along with the assessment of CETSCALE inIndian market. They define several socio-psychological and demographic factors that determine level of individual ethnocentric tendencies. Patriotism, conservatism, collectivism, salience, animosity and ethnic pride are socio-psychological factors that are positively correlated with consumer ethnocentrism, while openness to foreign culture is found to influence consumer ethnocentrism negatively. Among demographic factors, age is found to be positively correlated with preference for domestic products, and women are in general more ethnocentric consumers than men. On the other side, highly educated and richer people generally express lower levels ofconsumer ethnocentrism than poor and low educated people.

Analysis of Croatian university students' ethnocentric tendencies presented by Rešetar (2014) shows that those who are more ethnocentric consumers are women, students living in villages and students with lowest incomes, confirming the above listed antecedents of consumer ethnocentrism. HabiburRahman et al. (2011) conclude that, in case of Bangladesh, housewives tend to be more ethnocentric than other professions. Bangladeshi male tend to be more ethnocentric than female, and also, there is a positive correlation between level of education as well as age with level of consumer ethnocentrism. Saffu and Walker (2005) concluded that consumers (students) in country in transition (Russia) were more ethnocentric compared to their peers in Canada which is developed country, adding to the earlier studies that came up with similar findings.

Furthermore, consumer ethnocentrism is found to be positively related to consumer animosity. Akdogan et al. (2012) analyzed the effects of consumer ethnocentrism and consumer animosity on repurchase intent for American goods among Turkish consumers. They found significant and positive relation between consumer ethnocentrism and consumer animosity, but also concluded that both these elements were negatively related to customer loyalty, as well as the repurchase intent toward US products. However, customer loyalty was foundto be positively related to repurchase intent, but also to have significant moderating role in the interaction between consumer ethnocentrism and repurchase intent.

Reardon et al. (2005) investigated how ethnocentrism and economic development within transitional economies affects the formation of brand attitudes and attitude toward the ad with Kazakhstan and Slovenia representing transitional economies. They found the effect of ethnocentrism on attitude toward the ad 
to be stronger in the newly transitioning economy, while it affected attitude toward brand formation only indirectly through attitude toward the ad, not directly as predicted by previous research.

Ethnocentric tendencies of Bosnian consumers were assessed in the work of Marija Cutura (2011) and included population older than 15 years of age, in randomly selected households. The general conclusion was that the value of CETSCALE was relatively low, as compared to other, more developed countries. However, ethnicity and level of household income are found to have significant negative effect on the value of CETSCALE. It seems that Croats and Serbs are less ethnocentric consumers than Bosniaks. Also, she concluded that the consumer ethnocentrism is the most important predictor of evaluation, readiness to buy and the final purchase of domestic products.

Significant effect of nationalism and national identity on the level of consumer ethnocentrism in Bosnia and Herzegovina was confirmed by Vida et al. (2008). In the sample of 580 urban consumers, they found that ethnic affiliation has a direct effect on both consumer ethnocentrism and on domestic purchase bias. Bosniaks seem to be the most ethnocentric consumers in Bosnia and Herzegovina, followed by Serbs and then Croats. Similar findings were presented by Brkic et al. (2011)

Asil (2013) found that Turkish consumers have middle level consumer ethnocentrism tendency as measured by CETSCALE. A relationship was found between the Turkish consumers' socio-demographic characteristics and the levels of consumer ethnocentrism, as well as the correlation between consumers' political opinions and ethnocentric tendencies.

Candan et al. (2008) assessed consumer ethnocentric tendencies of Turkish students at the Faculty of Economics and Administrative Sciences, at Kocaeli University. It analyzed factors affecting purchasing decision of students regarding domestic and foreign products, as well as the effects of political stances of respondents on their ethnocentric attitudes. Results indicated that respondents were not highly ethnocentric consumers, in general, with slight variations in the levels of CETSCALE for respondents with different political stances.

\section{METHODOLOGY AND RESULTS}

The instrument used to assess consumer ethnocentric tendencies among university students at the International University of Sarajevo was so called CETSCALE developed by Shimp and Sharma in 1987. Studies using the CETSCALE reported high reliabilities, including Shimp, Shin and Sharma (1995), Netemeyer et al. (1991), Saffu and Walker (2005). 17 items were measured on the scale 1-7, with 1 being "strongly disagree" and 7 being "Strongly agree". Four 
additional questions assessing the demographic characteristics of respondents were included in the questionnaire regarding gender, household income level, education level and nationality. Income level was measured by an ordinal scale as follows: $1=$ less than 500 euros, $2=501-1000$ euros, $3=1001-1500$ euros, $4=1501-2000$ euros, and $5=$ more than 2000 euros.

Based on the previous findings obtained by conducting similar research in other countries, the present research will test several hypotheses.

H1: The mean value for the CETSCALE will be higher for respondents from Turkey than for respondents from Bosnia.

H2: Postgraduate students will show lower ethnocentric tendencies than freshmen, as measured by the CETSCALE.

H3: Consumer ethnocentric tendencies, as measured by the CETSCALE, will be positively correlated with females.

H4: Both Turkish and Bosnian students will express lower preferencefor domestic products compared to their peers from more developed countries, namely Canada.

The research included students of Bosnian and Turkish nationality studying at the International University of Sarajevo. The rationale for using students as a research population was to improve the homogeneity of the sample and to have comparable populations from two countries which should mirror the larger national attitudes as citizens of their respective countries. As the official language at the International University of Sarajevo is English, the survey was carried out in its original version without translating it to either Turkish or Bosnian language.

The total sample was 150 students including freshmen and postgraduate students and comprised of 48 Turkish students, 90 Bosnians and 12 students of other nationalities. The stratified sampling methodology was utilized with 100 respondents from the first study cycle (freshmen) and 50 postgraduate students. The reason for using these two groups of students is to have more pronounced effects of education level on consumer ethnocentric tendencies.

Table 1: CETSCALE items and reliability

\begin{tabular}{|cl|r|}
\hline ITEM & SCORES \\
\hline 1. & $\begin{array}{l}\text { Bosnian/Turkish should always buy Bosnian/Turkish - made } \\
\text { products instead of imports. }\end{array}$ & 0.8936 \\
\hline 2. & $\begin{array}{l}\text { Only those products that are unavailable in my country } \\
\text { should be imported. }\end{array}$ & 0.8937 \\
\hline 3. & $\begin{array}{l}\text { Buy Bosnian/Turkish products. Keep Bosnia/Turkey work- } \\
\text { ing. }\end{array}$ & 0.8940 \\
\hline 4. & Bosnian/Turkish-made products, first, last and foremost. & 0.8933 \\
\hline 5. & Purchasing foreign products is non-Bosnian/Turkish. & 0.8980 \\
\hline
\end{tabular}

Inquiry

2016/1 


\begin{tabular}{|c|c|c|}
\hline 6. & $\begin{array}{l}\text { It is not right to purchase foreign products, because it puts } \\
\text { Bosnian/Turkish people out of jobs. }\end{array}$ & 0.8922 \\
\hline 7. & $\begin{array}{l}\text { A real Bosnian/Turkish should always buy Bosnian/Turkish } \\
\text { products. }\end{array}$ & 0.8870 \\
\hline 8. & $\begin{array}{l}\text { We should purchase products manufactured in our country } \\
\text { instead of letting other countries get rich off us. }\end{array}$ & 0.8913 \\
\hline 9. & $\begin{array}{l}\text { It is always best to purchase Bosnian/Turkish -made prod- } \\
\text { ucts. }\end{array}$ & 0.8915 \\
\hline 10. & $\begin{array}{l}\text { There should be very little trading or purchasing of goods } \\
\text { from other countries unless out of necessary. }\end{array}$ & 0.894 \\
\hline 11. & $\begin{array}{l}\text { Bosnian/Turkish people should not buy foreign products, } \\
\text { because this hurts my country's business and causes unem- } \\
\text { ployment. }\end{array}$ & 0.8918 \\
\hline 12. & Restrictions should be put on all imports. & 0.9003 \\
\hline 13. & $\begin{array}{l}\text { It may cost me in the long run, but I prefer to support Bos- } \\
\text { nian/Turkish-made products. }\end{array}$ & 0.8908 \\
\hline 14. & $\begin{array}{l}\text { Foreigners should not be allowed to put their products on } \\
\text { our markets. }\end{array}$ & 0.901 \\
\hline 15. & $\begin{array}{l}\text { Foreign products should be taxed heavily to reduce their en- } \\
\text { try into my country. }\end{array}$ & 0.8999 \\
\hline 16. & $\begin{array}{l}\text { We should buy from foreign countries only those products } \\
\text { that we cannot obtain within our own country. }\end{array}$ & 0.8931 \\
\hline 17. & $\begin{array}{l}\text { Bosnian/Turkish consumers who purchase products in other } \\
\text { countries are responsible for putting Bosnian/Turkish people } \\
\text { out of work. }\end{array}$ & 0.8972 \\
\hline Test scale & & 0.8999 \\
\hline
\end{tabular}

*alpha scores on the deletion of an item

The data was collected in December 2015, and the questionnaire was administered by the author.Approximately $49 \%$ of the respondents among Bosnians were female, and about $41 \%$ of Turkish respondents were female. With respect to education level, $73 \%$ of Turkish students surveyed were freshmen, and $62 \%$ of Bosnian respondents were freshmen students. For analyzing the data, the statistical software STATA 11 was used.

CETSCALE's internal consistency was measured using Cronbach's alpha for the 17-item scale for the complete sample on the deletion of an item. The results are presented in Table 1. As it can be seen, all the scales are reliable as all the scores exceed the .70 rule, and internal consistency can be classified as "good" following the rule of thumb defined by George, D. \&Mallery, P. (2003). Several statistical tests were performed to explore the impact of demographic factors on the value of CETSCALE. Fisher's exact test was performed to examine differences in the demographic variables between students of two nations. Based on the results, there are no differences for gender $(\mathrm{p}=0.47)$ and education level $(\mathrm{p}=0.195)$, but the differences were noted for the income level $(\mathrm{p}=0.047)$. 


\begin{tabular}{|c|}
\hline Number of obs $=$ \\
\hline $\begin{array}{l}\text { Spearman's rho }=\quad-0.1877 \\
\text { Test of Ho: cetscale and nationality are inde- } \\
\text { pendent }\end{array}$ \\
\hline Prob $>|t|=$ \\
\hline $\begin{array}{l}\text { Spearman's rho }=\quad-0.2798 \\
\text { Test of Ho: cetscale and education_level are } \\
\text { independent }\end{array}$ \\
\hline Prob $>|t|=0.0009$ \\
\hline $\begin{array}{l}\text { Spearman's rho }=0.1249 \\
\text { Test of Ho: cetscale and gender are independent } \\
\text { Prob }>|t|=0.1428\end{array}$ \\
\hline $\begin{array}{l}\text { Spearman's rho }=0.0267 \\
\text { Test of Ho: cetscale and income are independent } \\
\text { Prob }>|t|=0.7554\end{array}$ \\
\hline
\end{tabular}

Spearman rank correlation test was performed for four demographic variables as shown in Table 2. The correlations (and $\mathrm{p}$-values) are $0.187(\mathrm{p}=0.0269) ; 0.279(\mathrm{p}=0.0009) ; 0.124$ $(\mathrm{p}=0.1428)$; and $0.026(\mathrm{p}=0.755)$ for nationality; education level; gender; and income level respectively. So, based on these findings, slightly positive correlation between CETSCALE and nationality indicates that, on average, Bosnian students tend to be more ethnocentric consumers than Turkish. There is also a positive correlation between education level and CETSCALE, meaning that more educated (postgraduate) students, on average, express greater consumer ethnocentric tendencies as compared to freshmen. Additionally, based on the Spearman rank correlation coefficient, it can be concluded that gender and income level are not significantly correlated with the value of CETSCALE.

Table 3: Simple within mean CETSCALE values for specific groups

\begin{tabular}{|l|l|}
\hline Avg_cetscale_Bosnians & 79.60 \\
\hline Avg_cetscale_Turkish & 74.22 \\
\hline Avg_cetscale_male & 75.13 \\
\hline Avg_cetscale_female & 80.70 \\
\hline Avg_cetscale_freshmen & 74.24 \\
\hline Avg_cetscale_postgraduate & 84.37 \\
\hline
\end{tabular}


groups shown in Table 3 confirms the above results, as it shows that the average value of CETSCALE for Turkish students (74.22) is slightly lower than for Bosnians (79.60). Also, the mean CETSCALE value for postgraduate students (84.37) was quite higher than for freshmen students (74.24). However, it also suggests that, on average, female students (80.70) are more ethnocentric consumers than male (75.13).

On the other side, results of inferential statistics where the simple regression was conducted with CETSCALE score being the dependent variable, and demographic characteristics of respondents independent, suggest positive relationship between CETSCALE values and education level of respondents at 5\% significance level, while the results for other independent variables indicate statistical insignificance.

\section{CONCLUSION}

The topic of consumer ethnocentrism has become frequent field of interest for many researchers in both developed and developing countries. Several conclusions were made based on a number of studies from countries with different development levels, which were conducted for populations with different demographic characteristics. In general, it is agreed that people from developed countries tend to be more ethnocentric consumers than those from developing countries.

The dominant view, when it comes to the age of the respondents, is that older people tend to be more ethnocentric consumers than younger. Additionally, people with higher levels of education are, in general, less ethnocentric compared to those with less education. Regarding the gender, it is concluded that women will be more ethnocentric consumers than men. The majority of these studies made use of CETSCALE for assessing the level of consumer ethnocentric tendencies, an instrument for which high reliability, validity, and stability was reported in studies conducted in USA, Russia, Canada and other countries. The present study is consistent with previous studies regarding reliability of CETSCALE, with the alpha scoreof 0.8999 for the whole sample.

Higher average CETSCALE values for Bosnians than for Turkish students was quite unexpected since the general perception (which was based on observation and understanding by the author) was that Turkish people are more ethnocentric consumers than Bosnians. Therefore, $\mathrm{H} 1$ was not supported by the evidence.

Additionally, the effect of education seems to be reverse as compared to previous studies, as the positive correlation was reported between education and consumer ethnocentric tendencies, which resulted in rejection of $\mathrm{H} 2$, while the results for gender confirm greater ethnocentric tendencies for female students 
than for male, irrespective of nationality and level of education, so we accept H3.Since both countries researched in this paper are classified as developing with upper middle-income level, it is hard to make any conclusions regarding the influence of the level of development on consumer ethnocentric tendencies. But, when compared to findings of similar research conducted in Russia and Canada (which is classified as developed country), it can be concluded that students from both Turkey and Bosnia tend to be more ethnocentric consumers than their peers from Russia and Canada. Therefore, we reject $\mathrm{H} 4$.

This study was concerned with the consumer ethnocentric tendencies of university students from two countries, Bosnia, and Turkey. Comparatively high values of CETSCALE among researched population might be a signal for local companies to focus more on this market segment in designing and marketing their products and services. However, to get the full insight into the ethnocentric behavior of nations, further research should involve larger population which would include people with more diverse demographic characteristics. Such a research might yield useful marketing implications on a larger scale for both Turkish and Bosnian marketers in their own countries, but also in trade between the two countries.

Additionally, it would be useful to conduct similar research in several years targeting the same population (university students) to follow the trend along with analyzing various campaigns which call citizens to buy domestic products instead of imports to ensure how successful they were. Such campaigns were very frequent in Bosnia in the recent period, especially 2015, but unfortunately, there was no previous research which would allow the author to make conclusions about their effects on consumers' ethnocentric tendencies.

\section{REFERENCES}

Agbonifoh, B. A., \&Elimimian, J. U. (1994). “Attitudes of developing countries to wards country-of-origin: Products in an era of multiple brands", Journal of International Consumer Marketing, no: II (4), 91-1

Akdogan, M.S., Ozgener, S., Kaplan, M., \&Coskun, A., (2012) “The Effects of Con sumer Ethnocentrism and Consumer Animosity on the re-purchase in tent: The moderating role of consumer loyalty", Emerging markets journal, Vol. 2, 2012

Asil, H., (2013) "An Empirical Study on Determining Ethnocentric Tendencies of Turkish Consumers", Istanbul University Journal of the School of Business, Vol. 42, No. 1

Brkic, N., Corbo, M., \&Berberovic, D.(2011) "Animosity in Consumer Behavior in Bosnia and Herzegovina and Implications for Companies" Economic Review - Journal of Economics and Business, 9 (1), 45-61.

Candan, B., Aydın, K. \& Yamamoto, G. T. (2008). “A research on measuring consumer ethnocentrism of young Turkish customers purchasing behavi ors", Serbian Journal of Management 3 (1) (2008), pp. 39 - 60 
M. Becic

Chowdhury T.A., \&IbnRahman, M., (2014) “Conceptualizing Consumer Ethnocentrism in a Developing Country: Validity and Applicability of CETSCALE in Bangladesh ", Journal of Asia-Pacific Business Volume 15, Issue 1, pages 27-53

Cutura, M. (2011). „The characteristics of consumers' ethnocentrism and possibilies to encourage the purchase of domestic products in Bosnia and Herzegovina", Sarajevo Business and Economics Review, no. 31/2011, pp.89-104

Durvasula, S., Andrews, C., Netemeyer, R. (1997) “Cross-cultural comparison of consumer ethnocentrism in the United States and Russia", Journal of In ternational Consumer Marketing no: 9(4), pp. 73-84

George, D., \&Mallery, P. (2003).“SPSS for Windows step by step: A simple guide and reference. 11.0 update (4th ed.)". Boston: Allyn\& Bacon

Good, L. K., Huddleston, P. (1995) "Ethnocentrism of Polish and Russian consumers: Are feelings and intentions related?",International Marketing Review no: 12(5), pp. 35-48.

HabiburRahman, M., Morshed, M., \&TakdirHossan, M., (2011) „Identifying and Measuring Consumer Ethnocentric Tendencies in Bangladesh", World Review of Business Research, Vol. 1. No. 1. March 2011. Pp. 71-89

Jain, S. K., \& Jain, R., (2013) „Consumer Ethnocentrism and Its Antecedents: An Exploratory Study of Consumers in India", Asian Journal of Business Research ISSN1178-8933 Volume 3 Number 12013

Luque-Martínez, T., Ibáñez-Zapata, J., \&del Barrio-García, S. (2000) "Consumer ethnocentrism measurement:An assessment of the reliability and validity of the CETSCALE in Spain",European Journal of Marketing, Vol. 34 Iss: 11/12, pp.1353 - 1374.

Mohammad, O., Ahmed, Z. U., Honeycutt Jr., E. D., \&Tyebkhan, T. H. (2000). "Does made-in matter to consumers? A Malaysian study of country of origin effect", Multinational Business Review, no: 8, (2), pp. 69-73

Papadopoulos, N. G., Heslop, L. A., \&Beraes, J. (1990). "National stereotypes and product evaluations in a socialist country”, International Marketing Re view, no: 7(1), 32-47

Pentz, C.,TerblancheN., \& Boshoff C., (2013) "Measuring Consumer Ethnocentrism in a Developing Context: An Assessment of the Reliability, Validity and Dimensionality of the CETSCALE, Journal of Transnational Management Volume 18, Issue 3, pages 204-218.

Saffu, K., \& Walker, J.H., (2005) „An Assessment of the Consumer Ethnocentric Scale (CETSCALE) in an Advanced and Transitional Country: The Case of Canada and Russia", International Jonrnal of Management Vol. 22 No. 4 December 2005

Sainy M., \&Jangalani S., (2012) „A study on ethnocentrism and buying behavior among B - School students", ELK Asia Pacific journals, Volume 3 Issue 4

Sepehr S., \&Kaffashpoor, A., (2012) "Measuring the Ethnocentric Tendencies of Iranian Consumers: An Assessment of Validity and Reliability of the CETSCALE", Journal of International Consumer Marketing Volume 24, Issue 4, pages 263-274

Terence, A. Shimp\& Sharma, S. (1987) “Consumer Ethnocentrism: Construction and Validation of the CETSCALE", Journal of Marketing Research, Vol. 24, No. 3 (Aug., 1987), pp. 280-289

Vida, I., Miller, C., Reardon, J., \& Kim, I., (2005) “The effects of ethnocentrism and economic development on the formation of brand and ad attitudes in transitional economies", European Journal of Marketing, Vol. 39 Iss: 7/8, pp.737 - 754

Vida, I., Dmitrovic, T., \&Obadia, C., (2008) "The Role of Ethnic Affiliation in Con sumer Ethnocentrism", European Journal of Marketing, 24 (3/4), 327343. 